\title{
from headquarters
}

\section{AMS Begins Restoration of Headquarters Building}

In May, AMS began many much needed repairs to the 190-year old house that serves as AMS Headquarters. Crews were hired to renovate several areas including the roof, gutters, staging, and railings.

The crews are erecting staging from the ground to roof height on the entire front and courtyard side to the shipping entrance. Rails and balusters are being manufactured to match the existing ones on the entire front of the house and from the courtyard side to the shipping entrance. The repairs and replacements to the roof and gutters consist of removing and replacing existing gutters with $16 \mathrm{oz}$ copper along the entire front section, down the courtyard section, and returning approximately 12 feet to the chimney. The copper icebelt will be removed and replaced in this area. In addition, all cracked, broken, and missing slate on the main roof will be repaired and replaced.

All of the wood and metal surfaces along the front of the building will be scraped, primed, and painted.

General repairs to the building will be made as needed. Repairs are expected to be completed mid-June. These are the first general restorations to the outside of the building since 1960 .

\section{Television Seals of Approval}

\begin{tabular}{lll}
\hline \hline & & \\
858 & James Spann & 1996 \\
859 & Austen L. Onek & 1996 \\
860 & Mark T. Modrak & 1996 \\
861 & Bethany Solomon & 1996 \\
862 & Terri A. DeBoer & 1996 \\
863 & Kenneth A. Nagel & 1996 \\
864 & Frank Mamola & 1996 \\
& & \\
\hline
\end{tabular}

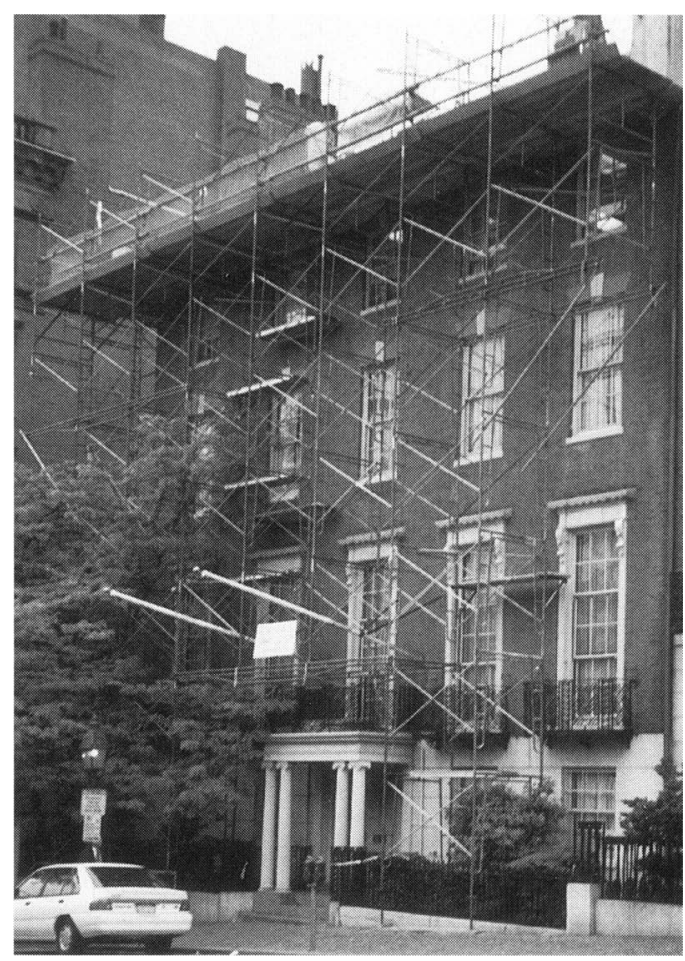

Scaffolding along the front and sides of AMS Headquarters allows renovation crews to repair the building's roof, gutters, railings, and to paint the wood and metal on the front of the house.

\section{Updates to the AMS Web Page}

- May's edition of the AMS Newsletter

- Changes and updates to Contacts at AMS

- Careers in Atmospheric Research

- Updates and additions to AMS Meetings

- AMS Journals' Tables of Contents

Look us up at http://www.ametsoc.org/AMS 


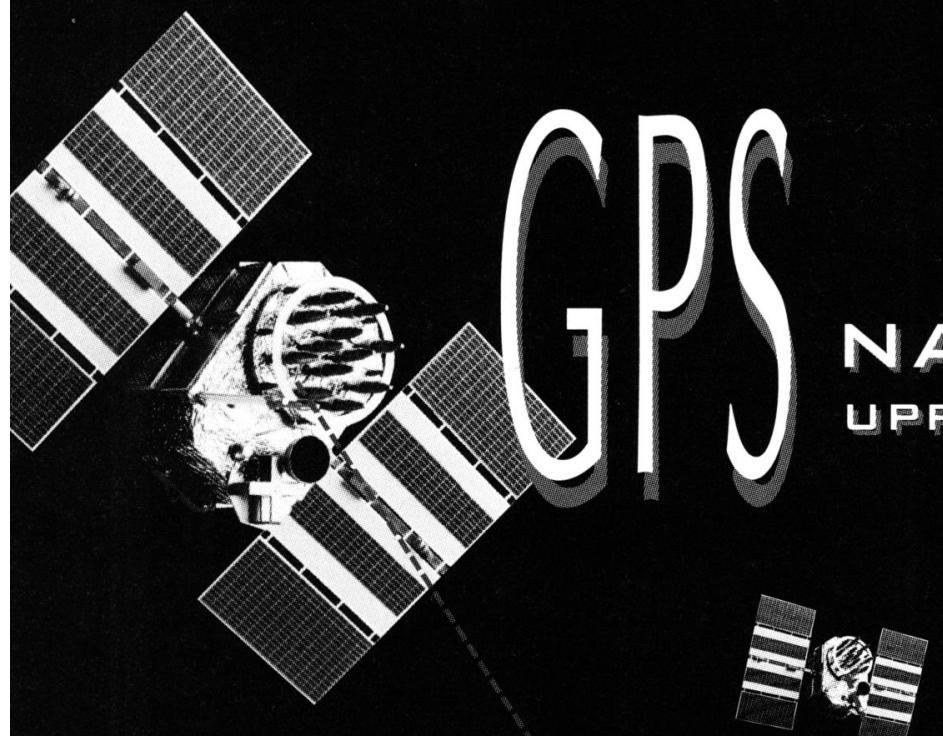

- Worldwide, 24-Hour GPSonde ${ }^{T M}$ Soundings

- Fixed or Mobile Operation

- Automated WMO \& STANAG Messages

- Differential or Autonomous Mode Using Codeless GPS

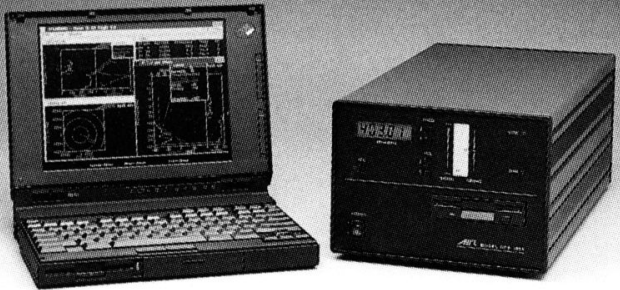

- Narrow Band FM Telemetry for Reliable, Interference-Free Reception

Utilizing navigation signals from the Global Positioning System, NAVAIR/GPS provides reliable, accurate, synoptic sounding data under all weather conditions, anywhere on the globe, at all times. The cost/benefit ratio of AIR's NAVAIR / GPS technology means affordable systems and radiosondes for all budgets.

Flexibility: NAVAIR/GPS ground stations can be configured for use with AIR's GPSondes, GPS dropwindsondes, or GPS rocketsondes to provide reliable rawinsonde sounding data. One-person release and operational simplicity allow flexible, error-free sounding to $30 \mathrm{~km}$ when the ground station is either fixed or in a moving vehicle. This technology works without knowledge of GPS codes and during periods when selective availability and anti-spoofing are present. GPS windfinding is combined with AIR's high-accuracy pressure, temperature and relative humidity sensors to produce accurate, precise atmospheric data.

Applications: - National weather service synoptic forecasts - Meteorological research • Boundary layer meteorology • Air pollution meteorology $\bullet$ Hurricane tracking • Emergency response - Defense applications in artillery, on ships, aircraft or vehicles • Test-range atmospheric studies • Refractive index measurement

Enter the Future - Now. Learn more about the GPS revolution in upper air soundings and how to upgrade your existing systems. Contact AIR/Atmospheric Instrumentation Research • 8401 Baseline Road • Boulder, Colorado 80303 Phone: (303) 499-1701 • Fax: (303) 499-1767 